\title{
Interventional creation of an endogenous reverse Potts shunt in an infant with pulmonary hypertension and genetic surfactant disorder - a case report
}

\author{
Hannes Sallmon ${ }^{1}$, Felix Berger ${ }^{1,2,3}$, Sven C. Weber ${ }^{1}$, Hendrik S. Fischer ${ }^{4}$, Georg Hansmann ${ }^{5}$, \\ Bernd Opgen-Rhein ${ }^{1}$
}

${ }^{1}$ Department of Pediatric Cardiology, Charité-Universitätsmedizin Berlin, Berlin, Germany; ${ }^{2}$ Department of Congenital Heart Disease/Pediatric Cardiology, Deutsches Herzzentrum Berlin (DHZB), Berlin, Germany; ${ }^{3}$ Deutsches Zentrum für Herz- und Kreislaufforschung, Partnersite Berlin (DZHK), Berlin, Germany; ${ }^{4}$ Department of Neonatology, Charité-Universitätsmedizin Berlin, Berlin, Germany; ${ }^{5}$ Department of Pediatric Cardiology and Critical Care, Hannover Medical School, Hannover, Germany

Correspondence to: Hannes Sallmon, MD. Department of Pediatric Cardiology, Charité-Universitätsmedizin Berlin, Augustenburger Platz 1, 13353 Berlin, Germany. Email: hannes.sallmon@charite.de.

\begin{abstract}
Reverse Potts shunt is a palliative procedure aimed at decompressing the pressure-overloaded right ventricle in severe pulmonary hypertension $(\mathrm{PH})$. We, herein, report the first case of an interventional creation of an "endogenous" reverse Potts shunt by stenting a pre-existing small but patent ductus arteriosus (PDA) in a 2 months old female infant with severe, supra-systemic PH, associated with a novel combination of a compound heterozygous $A B C A 3$ mutation and additional heterozygous genetic variants of surfactant protein B $(S F T P B)$ and C $(S F T P C)$. The aforementioned combination of human genetic mutations has not been described before in viable infants, children or adults. The catheter intervention was performed via percutaneous femoral arterial access and was well-tolerated. Subsequently, the infant improved by means of clinical status, echocardiographic systolic right ventricular (RV) function, and serum NT-proBNP levels as biomarker of right atrial and RV pressure load. In conclusion, this single case report suggests that interventional stenting of a pre-existing PDA to create an "endogenous" reverse Potts shunt is feasible and efficacious in infants less than 3 months old with severe $\mathrm{PH}$ and impending RV failure associated with developmental lung disease.
\end{abstract}

Keywords: ABCA3; SFTPB; SFTPC; neonate; ductus arteriosus; ductal stenting; Potts shunt

Submitted Feb 07, 2020. Accepted for publication Mar 19, 2020.

doi: $10.21037 /$ cdt.2020.03.11

View this article at: http://dx.doi.org/10.21037/cdt.2020.03.11

\section{Introduction}

Genetic disorders of surfactant production and metabolism (ABCA3, SFTPB, SFTPC) present with a high phenotypic variety, ranging from severe respiratory failure at birth to interstitial lung disease in older children and adults (1). Patients may also develop pulmonary hypertension $(\mathrm{PH})$, which can be life-limiting, if right ventricular (RV) failure is impending $(1,2)$. In addition to standard treatment protocols aimed at treating the underlying lung disease (e.g., corticosteroids, hydroxychloroquine, and supportive measures), pulmonary vasodilators have been used in patients with $\mathrm{PH}$ associated with developmental lung disease with different results (1).

Reverse Potts shunt creation by ductal stenting and balloon atrial septostomy (BAS) represent palliative treatment options in severe, systemic-to-supra-systemic PH. These procedures decompress the right atrium (BAS) or the RV (reverse Potts shunt) and result in a hemodynamic situation that is similar to the physiology of Eisenmenger patients. However, only the reverse Potts shunt can prevent RV failure mid- to long-term, andin contrast to BAS-preserves adequate preductal arterial 


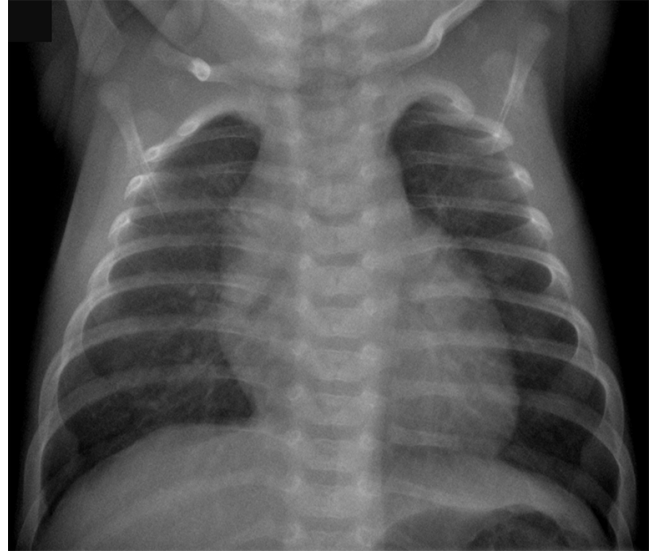

Figure 1 Chest X-ray on the first day of life. The chest X-ray did not indicate any specific pulmonary pathology.

oxygen supply to the upper body, including heart and brain (3-5). Reverse Potts shunt circulation is achieved by either surgical or interventional creation of a connection between the descending aorta and the pulmonary artery $(\mathrm{PA})$, which secures sufficient cardiac output, at the expense of hypoxemia in the lower half of the body (3-5). Although reverse Potts shunt creation is recommended as palliation or bridge-totransplantation in current guidelines on pediatric $\mathrm{PH}(6)$, its use has not been previously reported in young infants with severe $\mathrm{PH}$ associated with developmental lung disease.

Here, we report the first case of interventional creation of reverse Potts shunt by stenting a pre-existing ductus arteriosus ("endogenous" Potts shunt) in a female infant with severe $\mathrm{PH}$ associated with a compound heterozygous $A B C A 3$ mutation and additional, possibly disease-associated heterozygous $S F T P B$ and $S F T P C$ variants. We present the following case in accordance with the CARE Guideline (available at http://dx.doi.org/10.21037/cdt.2020.03.11).

\section{Case presentation}

A term female infant $(41+3$ weeks of gestation, 3,540 g) presented with tachypnea and hypoxemia after spontaneous delivery. Echocardiography on the first day of life revealed a moderately elevated RV systolic pressure (RVSP) of 70$80 \mathrm{mmHg}$ [RVSP $70 \mathrm{mmHg}$ plus right atrial v wave, estimated by the maximum velocity of the tricuspid regurgitation (TR) jet by CW Doppler] and a small persistent foramen ovale, but no cardiac anomalies. The infant was diagnosed with persistent pulmonary hypertension of the newborn (PPHN) and admitted to the neonatal intensive care unit. She required respiratory support by continuous positive airway pressure for 60 hours and supplementary oxygen for 80 hours. Empiric antibiotic treatment with ampicillin and gentamicin was performed for 48 hours despite normal laboratory testing and chest X-ray results (Figure 1). The infant improved clinically and was discharged on day of life 7 in stable condition, with normal breathing and normal peripheral oxygen saturations.

In the following weeks of life, the parents recognized drinking difficulties and consulted their community-based pediatrician who noted moderate tachypnea and referred the infant for pediatric cardiology consultation.

Upon admission, we saw an 8-week-old female infant (body weight $4.4 \mathrm{~kg}$, body surface area $0.27 \mathrm{~m}^{2}$ ) with echocardiographic signs of supra-systemic PH (RVSP $140 \mathrm{mmHg}$ by TR jet) and imminent RV failure, characterized by RV dilation and severely depressed systolic RV function: grade 2-3 TR, decreased tricuspid annular plane systolic excursion (TAPSE, $7 \mathrm{~mm}$ ) and pulmonary artery acceleration time (PAAT $44 \mathrm{~ms}$ ), increased endsystolic RV/LV diameter ratio (18 mm/3 mm, Figure $2 A)$ and end-systolic LV eccentricity index (LV-EI, 3.2). A residual patent ductus arteriosus (PDA) showed exclusive right-to-left shunt with clear narrowing at the junction to the descending aorta (minimum ductal diameter $0.8 \mathrm{~mm}$ ). In an attempt to reopen the constricting, flow-restrictive PDA, the infant immediately received continuous prostaglandin E1 infusion (20 ng/ $\mathrm{kg} / \mathrm{min})$. In addition, we initiated milrinone and pulmonary vasodilatory treatment with sildenafil and bosentan. Since the PDA did not reopen sufficiently with PGE1 infusion while there was still suprasystemic PH and imminent RV failure, we performed cardiac catheterization. We confirmed supra-systemic $\mathrm{PH}$ (113\%) with a PA pressure of 71/29 (mean 45) $\mathrm{mmHg}$ and an ascending aortic pressure of $55 / 23$ [mean 40] $\mathrm{mmHg}$, a PA wedge pressure (PAWP) of $9 \mathrm{mmHg}$, a mean transpulmonary pressure gradient (TPG) of $36 \mathrm{mmHg}$, a diastolic TPG of $20 \mathrm{mmHg}$, a pulmonary-to-systemic blood flow ration $(\mathrm{Qp} / \mathrm{Qs})$ of $0.93: 1$, an estimated indexed pulmonary vascular resistance (PVRi) of $8.9 \mathrm{WU} \times \mathrm{m}^{2}$, and a pulmonary-to-systemic resistance ratio of 1.27:1 (PVR/ SVR). Subsequently, a Cordis PALMAZ Blue ${ }^{\mathrm{TM}}$ Stent ( $4 \mathrm{~mm}$ $\times 15$ mm, 11 bar, Cardinal Health Germany, Norderstedt, Germany) was percutaneously implanted via a 4 French sheath in the right femoral artery under general sedation (Figure 2B,C,D,E), without any complication. Of note, the above flow data (Qs, Qp, PVR, SVR) are rough estimates using the Fick principle, as this patient had anatomically two possible sources of pulmonary blood flow, PA and PDA. 

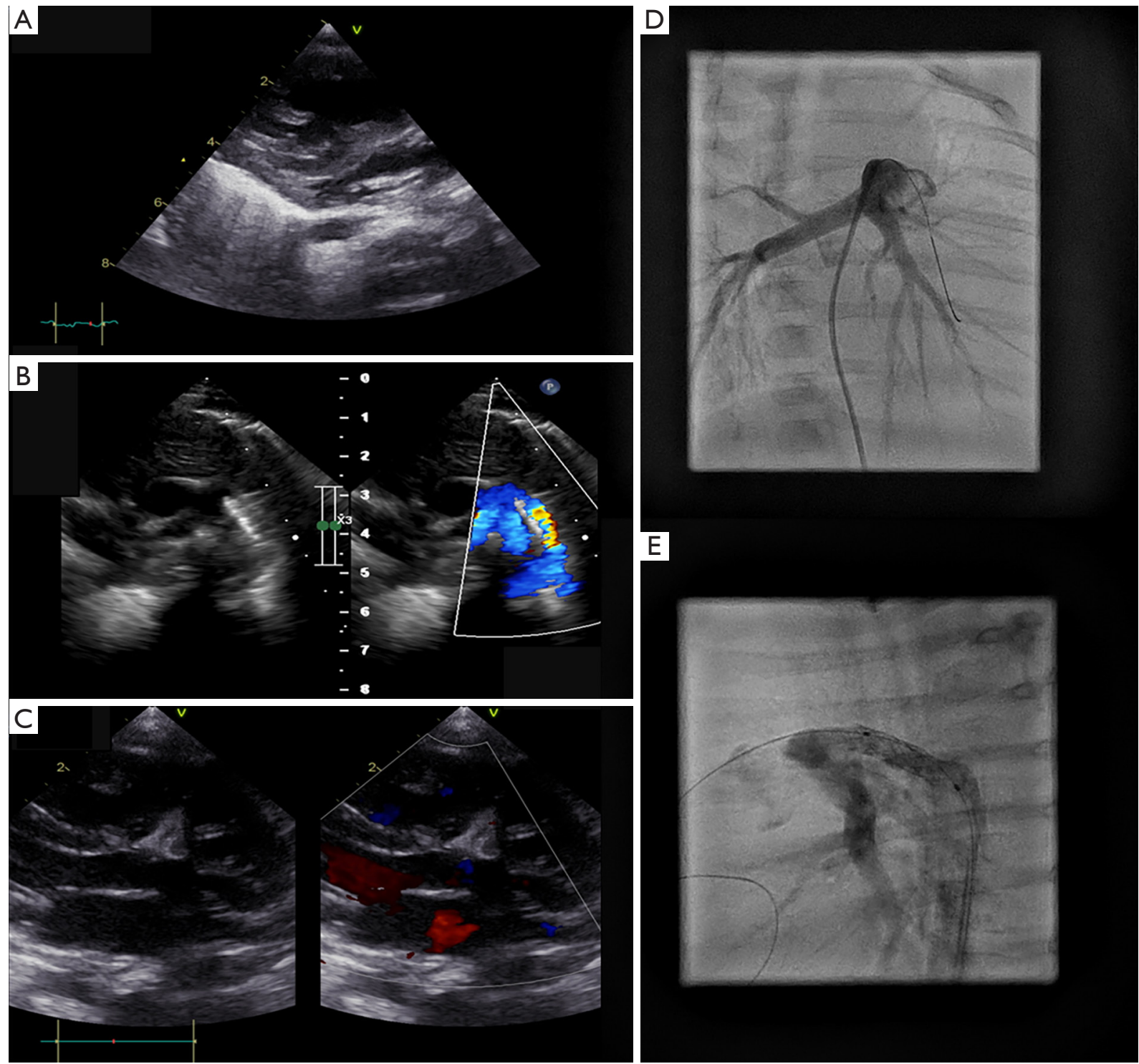

Figure 2 Echocardiography and pulmonary angiography after stenting of the restrictive ductus arteriosus in an infant with $\mathrm{PH}$ and imminent RV failure. (A) Echocardiographic parasternal long axis view on admission shows a severely compressed left ventricle; (B) echocardiographic parasternal short axis after Ductus arteriosus stenting reveals systolic right-to-left shunt; (C) echocardiographic parasternal long axis view after endogenous Potts shunt shows marked decompression of the left ventricle; (D) pulmonary angiography; (E) angiography-guided ductal stent placement.

However, we feel that the above-mentioned calculations are adequate in our case due to exclusive ductal right-to-left shunting. Thus, the PA oxygen saturation was most likely not contaminated by highly saturated ductal blood flow.

The PDA-stenting was well-tolerated and substantially improved echocardiographic variables of RV function. Blood flow direction through the stented ductus was rightto-left in systole, and left-to-right in diastole, indicating a diastolic PAP/SAP ratio of $<1$ and a PVR/SVR ratio of $<1$. TR, TAPSE and PAAT improved to grade $1,12 \mathrm{~mm}$, and $70 \mathrm{~ms}$, respectively. In addition, end-systolic RV/LV diameter ratio and LV-EI decreased immediately after the procedure to $9.5 \mathrm{~mm} / 7.3 \mathrm{~mm}$ and 1.9 , and further improved after 1 week to $10.5 \mathrm{~mm} / 8.5 \mathrm{~mm}$ and 1.4 , respectively, indicating pressure-unloading of the RV and less end-systolic compression of the LV. Serum NT-proBNP levels decreased 


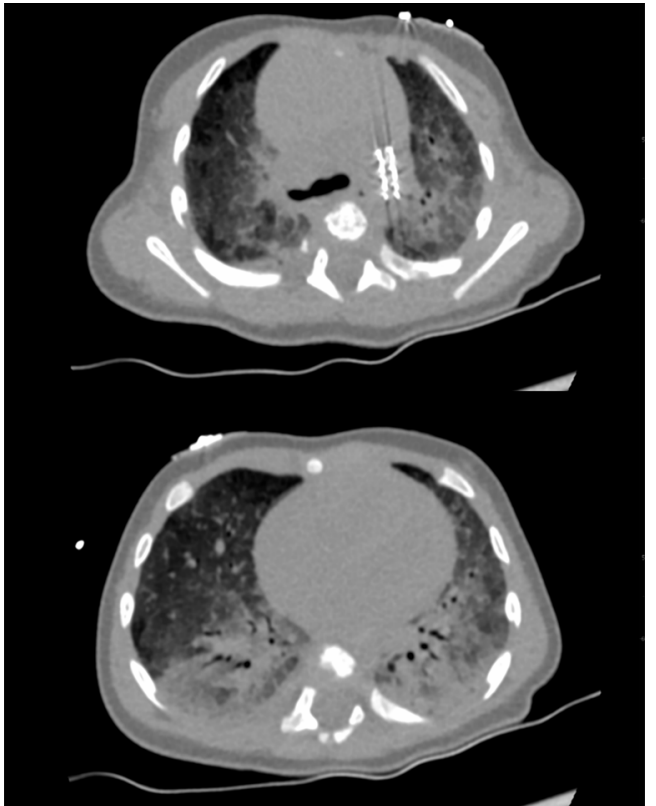

Figure 3 Computerized chest tomography. The CT revealed ground glass opacities and unspecific infiltration in both lungs, consistent with lung disease due to disorders of surfactant synthesis and/or metabolism. CT, computed tomography.

from 8,049 $\mathrm{ng} / \mathrm{L}$ upon admission to 2,285 $\mathrm{ng} / \mathrm{L} 3$ days after PDA stenting. The 9 -week-old infant (4.85 kg bodyweight) could be discharged on oral sildenafil, bosentan, L-arginine, magnesium, and nasal oxygen (1/min 100\%).

We initiated genetic panel testing for pulmonary arterial hypertension and interstitial lung disease. We found a novel combination of a compound heterozygous mutation in the ABCA3 gene (NM_001089.2:c.2890G > A, Gly964Ser, exon 21; NM_001089.2:c.2125C > T, Arg709Trp, exon 17) and heterozygous polymorphisms in the $S F T P B$ (NM_198843.2:c.428T > C, Ile143Thr, exon 5, autosomal recessive) and SFTPC genes (NM_003018.3:c.413C > A, Thr138Asn, Exon 4; NM_003018.3:c.557G > A, Ser186Asn, Exon 5, autosomal dominant).

High-resolution chest computed tomography (HRCT) showed typical signs of developmental lung disease associated with disorders of surfactant protein synthesis and/ or metabolism (Figure 3). Subsequently, the infant received methylprednisolone courses and hydroxychloroquine was initiated. NT-proBNP levels further decreased to $1,180 \mathrm{ng} / \mathrm{L}$ and right heart function remained stable while growth and development were appropriate during the first 5 months of life.

\section{Discussion}

Herein, we report on the first creation of an endogenous Potts shunt by stenting a pre-existing, restrictive PDA in an infant with severe, supra-systemic $\mathrm{PH}$ and impending $\mathrm{RV}$ failure associated with developmental lung disease. There is an ongoing debate on the optimal management of infants with lung disease and $\mathrm{PH}$ (group $3 \mathrm{PH}$ ) (6). Pulmonary vasodilative therapy is often applied, but has not been systematically studied in this patient population (1), and the response to pharmacotherapy is very heterogeneous and usually limited $(1,2)$. Furthermore, it is still unclear which factors determine the response to pulmonary vasodilators in infants with $\mathrm{PH}$ and lung disease due to a proven genetic mutation. The vast variety in both pheno- and genotypes in infants with genetic surfactant protein and/or $A B C A 3$ disorders highlights the critical need for further research $(7,8)$, including patient registries (9), in order to identify clinical and genetic determinants of treatment response and outcome.

Our patient exhibited a compound heterozygous $A B C A 3$ mutation. Both mutations (NM_001089.2:c.2890G > A and NM_001089.2:c.2125C > T) have been previously described as part of different compound heterozygous mutations with varying pulmonary phenotypes in infants and adults $(7,8,10)$. However, the combination of $A B C A 3$ mutations we detected has not been reported yet in any human heart-lung conditions. In addition, we found possibly disease-associated heterozygous variants in the $S F T P B$ and $S F T P C$ genes.

Our case highlights that unexplained $\mathrm{PPHN}$ requires a close and timely cardiac follow-up to detect chronic $\mathrm{PH}$ of infancy. The etiology can be either idiopathic or due to several heart and lung diseases or systemic disorders (6). Early genetic testing might lead the way to suspect the correct, etiological diagnosis before more invasive testing, such as CT scans or lung biopsies, needs to be performed. In infants with supra-systemic $\mathrm{PH}$, an attempt to pharmacologically reopen a (residual, flow-restrictive) PDA provides an elegant method to rapidly decompress a pressure-overloaded, failing $\mathrm{RV}$. In infants with $\mathrm{PH}$ associated with interstitial and/or diffuse lung disease, the response to pulmonary vasodilative therapy is heterogeneous and often limited (1), thus making interventional procedures, such as reverse Potts shunt creation or BAS, attractive options as a palliation or as a bridge to transplantation $(3,6,11)$.

In conclusion, we report the first interventional creation of an endogenous Potts shunt by ductal stenting, in an infant with severe $\mathrm{PH}$ associated with lung disease caused by a 
combined genetic disorder of surfactant metabolism and/or synthesis. Endogenous Potts shunt creation by stenting a preexisting PDA is suitable for long-term management of even small infants with severe $\mathrm{PH}$ associated with lung disease. Certainly, further research on the optimal management of infants with $\mathrm{PH}$ associated with diffuse or interstitial lung disease is warranted in order to improve outcomes in this especially diverse and vulnerable patient population.

\section{Acknowledgments}

Funding: None.

\section{Footnote}

Provenance and Peer Review: This article was commissioned by the Guest Editors (Martin Koestenberger, Harm-Jan Bogaard and Georg Hansmann) for the series "Right Ventricular Dysfunction" published in Cardiovascular Diagnosis and Therapy. The article was sent for external peer review organized by the Editor-in-Chief and the editorial office.

Conflicts of Interest: All authors have completed the ICMJE uniform disclosure form (available at http:// dx.doi.org/10.21037/cdt.2020.03.11). The series "Right Ventricular Dysfunction" was commissioned by the editorial office without any funding or sponsorship. The authors have no other conflicts of interest to declare.

Ethical Statement: The authors are accountable for all aspects of the work in ensuring that questions related to the accuracy or integrity of any part of the work are appropriately investigated and resolved. All procedures performed in studies involving human participants were in accordance with the ethical standards of the institutional and/or national research committee(s) and with the Helsinki Declaration (as revised in 2013). Parental written informed consent was obtained for publication of this manuscript and any accompanying images.

Open Access Statement: This is an Open Access article distributed in accordance with the Creative Commons Attribution-NonCommercial-NoDerivs 4.0 International License (CC BY-NC-ND 4.0), which permits the noncommercial replication and distribution of the article with the strict proviso that no changes or edits are made and the original work is properly cited (including links to both the formal publication through the relevant DOI and the license). See: https://creativecommons.org/licenses/by-nc-nd/4.0/.

\section{References}

1. Bromley S, Vizcaya D. Pulmonary hypertension in childhood interstitial lung disease: a systematic review of the literature. Pediatr Pulmonol 2017;52:689-98.

2. Ota C, Kimura M, Kure S. ABCA3 mutations led to pulmonary fibrosis and emphysema with pulmonary hypertension in an 8-year-old girl. Pediatr Pulmonol 2016;51:E21-3.

3. Hansmann G. Pulmonary hypertension in infants, children, and young adults. J Am Coll Cardiol 2017;69:2551-69.

4. Boudjemline Y, Patel M, Malekzadeh-Milani S, et al. Patent ductus arteriosus stenting (transcatheter Potts shunt) for palliation of suprasystemic pulmonary arterial hypertension: a case series. Circ Cardiovasc Interv 2013;6:e18-20.

5. Valdeomillos E, Jalal Z, Boudjemline Y, et al. Transcatheter ductus arteriosus stenting in paediatric cardiology: indications, results and perspectives. Arch Cardiovasc Dis 2020;113:129-41.

6. Hansmann G, Koestenberger M, Alastalo TP, et al. 2019 updated consensus statement on the diagnosis and treatment of pediatric pulmonary hypertension: the European Pediatric Pulmonary Vascular Disease Network (EPPVDN), endorsed by AEPC, ESPR and ISHLT. J Heart Lung Transplant 2019;38:879-901.

7. Kröner C, Wittmann T, Reu S, et al. Lung disease caused by ABCA3 mutations. Thorax 2017;72:213-20.

8. Wambach JA, Casey AM, Fishman MP, et al. Genotypephenotype correlations for infants and children with ABCA3 deficiency. Am J Respir Crit Care Med 2014;189:1538-43.

9. Bush A, Cunningham S, de Blic J, et al. European protocols for the diagnosis and initial treatment of interstitial lung disease in children. Thorax 2015;70:1078-84.

10. Flamein F, Riffault L, Muselet-Charlier C, et al. Molecular and cellular characteristics of ABCA3 mutations associated with diffuse parenchymal lung diseases in children. Hum Mol Genet 2012;21:765-75.

11. Eldridge WB, Zhang Q, Faro A, et al. Outcomes of lung transplantation for infants and children with genetic disorders of surfactant metabolism. J Pediatr 2017;184:157-64.e2.

Cite this article as: Sallmon H, Berger F, Weber SC, Fischer HS, Hansmann G, Opgen-Rhein B. Interventional creation of an endogenous reverse Potts shunt in an infant with pulmonary hypertension and genetic surfactant disorder-a case report. Cardiovasc Diagn Ther 2020;10(5):1696-1700. doi: 10.21037/ cdt.2020.03.11 